\title{
\$7 $\begin{aligned} & \text { MEX } \\ & \text { B XXI BEKE }\end{aligned}$
}

Саврыга К.П.

\section{ВОЙНА С ТЕРРОРИЗМОМ КАК ВООРУЖЕННЫЙ КОНФЛИКТ: DE LEGE LATA И DE LEGE FERENDA}

Аннотация: В современноем мире перед многими государствами встала серьезная угроза тероризма. Террористические организации на сегодняшний день часто предтавляют собой более серьезную силу, нежели несколько десятилетий назад, многие в настоящее время (например Исламское Государство) обладают венными возможностями сравнимыми с некоторыми государствами. Что ставит перед мировым сообществом вопрос о допустимости применения парадигмы вооруженного конфликта к отношениям по борьбе с указанными террористами, так как она дает государству больше возможностей для применения силь 8 отношении противника, нежели парадигма прав человека. В настоящей статье автор исследует основнье источники международного гуманитарного права: договора, протоколь дипломатических конференций и судебные решения для того, что бы определить возможно ли квалифицировать войну с терроризмом как вооруженный конфликт. Также исследуются различные доктринальные подходы, характеризующие войну с терроризмом как третью форму вооруженного конфликта. В конце, автор приходит к выводу, что de lеgе lata война с терроризмом не может считатья вооруженным конфликтом, так как для международного вооруденного конфликта террористической организации не достает правосубъектности, а для вооруженного конфликта немеждународного характера, насиле, которое совершается террористическими группа как правило не удовлетворяет критеорию интенсивности (однако существуют редкие исключения). Однако, это не препятствует квалификации отдельных эпизодов войны с терроризмом как вооруженных конфликтов. Касаемо вопроса de lege ferenda, автор приходит к выводу об отсутствии оснований для регулирования войны с терроризмом правом вооруженных конфликтов.

Ключевые слова: Терроризм, право вооруженных конфликтов, немеждународный вооруженный конфликт, международный вооруженный конфликт, вооруженный конфликт, международное гуманитарное право, война с терроризмом, международное право, негосударственные акторы, ответственость государства.

Abstract: In the modern world many nations face the serious threat of terrorism. Today, the terrorist organizations often represent a more powerful force than few decades ago, and many of them currently (for example the so-called Islamic State or ISIS) possess military capabilities comparable to some countries, which poses before the global community a question of allowance of application of the paradigm of an armed conflict to the relations on the fight with the aforementioned terrorists, as it gives the state greater freedom of using force against the enemy than the paradigm of human rights. The author studies various doctrinal approaches that characterize war on terror as the third form of armed conflict. In the end, the author concludes that the de lege lata war on terror cannot be considered an armed conflict, since for an international armed conflict the terrorist organization lacks corporate personhood, and for non-international military conflict, the violence that is caused by the terrorist organizations usually does not meet the criteria of intensity (even though there are some exceptions).

Keywords: International humanitarian law, armed conflict, international armed conflict, non-international armed conflict, law of armed conlfict, terrorism, war on terror, international law, non-state actors, state responsibility.

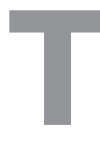
ермин «Война с терроризмом» подразумевает, что деятельность государства или группы государств по противодействию террористической деятельности подпадает под определение вооруженного конфликта. Так после атаки 11 сентября президент США Дж.Буш выступил с заявлением:
«Наша война с терроризмом начинается с Аль-Каиды, но она не закончится на ней. Она не закончиться пока последний террорист не будет остановлен или уничтожен»[91,p.1348].

Конечно в истории много примеров, когда государства объявляли «войну» различным нежелательным проявлениям: преступности, бедности, нарко- 
тикам и т.д. Но во всех этих случаях слово «война» являлась лишь риторическим приемом, призванным подчеркнуть важность борьбы с чем-то. Однако, «война с терроризмом» оказалась не из этой серии. Попытки министерства обороны США изменить термин «война с терроризмом» на «глобальное противостояние насильственному экстремизму»не встретило поддержки среди администрации[72,p.2] [80]. Таким образом, необходимо проанализировать, имеет ли термин «война с терроризмом»какое либо юридическое значение в действующем международном праве или оно является лишь риторическим приемом, тем более, что на этот счет существуют различные точки зрения[60,p.349][3,p.800-818][8,p.810][49,p.454-479].

Так как в международном праве нет такого понятия как террорист, в международном гуманитарном праве, соответственно, наличие или отсутствие терроризма никак не влияет на применение норм международного гуманитарного права самого по себе. Некоторые авторы утверждают, что нормы международного гуманитарного права должны применяться к войне с терроризмом, так как она является или международным военным конфликтом или военным конфликтом немеждународного характера[52,p.41-47][56,p.291-296]. Очевидно, что США и иные страны, борющиеся с терроризмом, составляют одну сторону конфликта. Но что же делать с другой стороной?

\section{Война с терроризмом как международный вооруженный конфликт}

Традиционный сценарий, с расчетом на который разрабатывалось международное гуманитарное право, не предусматривает конфликта между государством и международной террористической организацией[4,p.348]. Хотя, в то же время, нормы международного гуманитарного права при определенных условиях, могут регулировать вооруженный конфликт между государством и группой террористов[69,p.431-434]. Таким образом, нам необходимо разобраться, может ли противостояние между государством и террористическими группами, подпадать под определение статьи 2 Женевских Конвенций, которые обращаются к Высоким Договаривающимся Сторонам, что подразумевает государства?

Для того, что бы начать международный вооруженный конфликт необходимо, что бы насилие, которое одна сторона применяет по отношению к другой достигло бы определенного уровня. Конечно, требования к началу международного вооруженного конфликта, в плане необходимо уровня насилия существенно ниже, чем к немеждународному, однако, далеко не каждая ситуация, имеющая террористический характер может быть квалифицированна как вооруженный конфликт[70,p.44]. Особенно в ситуации, когда цель атаки представляет собой гражданский объект, что особенно важно, так как основанная мишень террористических атак именно они. По общему правилу, атака любой интенсивности на военный объект выполняет требование для начала вооруженного конфликта.

Вопрос об уровне необходимого насилия не стоит путать с вредом от атаки, который может вызвать право на самооборону у государства. Хотя, такие акты рассматриваются как оправдание на использование военной силы и как следовательно применения норм гуманитарного права.

Так Rowles утверждает, что для начала вооруженного конфликта, террористы должны применить силу такого качества и количества, которая бы повлекла за собой вооруженный конфликт, если бы она была применена государством[74,p.314]. Так, утверждалось, что качественный уровень насилия и жертв, в результате атаки 11 сентября, даже как отдельный акт, является достаточным для того, что бы начать вооруженный конфликт[94,p.149-150] [31,p.433-443]. Однако, это спорно, насколько это была угроза нового порядка, так как что -то подобное в США было и раньше[82,p.160-161]. Однако, если на качественном уровне такая угроза уже присутствовала, то на количественном она действительно могла быть сравнима с военной такой. Так атака во время Второй мировой войны на ПерлХарбор привела к 2.403 убитым, тогда как террористическая атака на Всемирный торговый центр к 2.823[11,p.856]. Если же принять во внимание международную реакцию, то становится очевидно, что уровень насилия был воспринят как достаточный для начала вооруженного конфликта[85][86] [81][58][59][9,p.589-590][19,p.921-922][24,p.839-842] [14,p.234][25,p.885-889][30,p.29-45][63,p.326][97,p.5] [96,p.26-27]. Хоть и не единогласно[66][2,p.358-359] [66,p.71]. Даже Rowles считает, что единственная террористическая атака не может быть основание для военного конфликта, в то же время, так и ответная акция возмездия от государства не удовлетворяет требованию интенсивности[74,p.314], хотя есть и противоположная точка зрения[99,с.58].

Даже если мы допустим, что уровень насилия, необходимый для начала вооруженного конфликта 
был достигнут, то другие требования к международным вооруженным конфликтам так же должны быть выполнены, однако, классическая формулировка международного вооруженного конфликта предусматривает, что сторонами конфликта являются государства. Т.е. даже если рассматривать такие понятия как «новая форма военных конфликтов»[32,p.330] или «неконвенциональная война»[79,p.197], то все равно они не могут быть признаны международным конфликтом, с террористической организацией на другой стороне.

Однако, были предприняты теоретические попытки подвести конфликт с террористическими организациями под определение статьи 2 Конвенций[10,p.4][17,p.523-533][19,p.921-922] [28,p.2-4][69,p.424][98,p.126-129]. Так, это предположение подкреплялось тем, что США находятся в состоянии войны с Аль-Каидой с 1996 года, когда та объявила джихад США[83]. Таким образом, утверждалось, что парадигма вооруженного конфликта используется обеими сторонами[17,p.523][84,p.59]. Одним из аргументов, которым обосновывалась необходимость применения военной парадигмы для борьбы с терроризмом, вместо правоохранительной, являлся тот факт, что процессуальные гарантии, существующие в правоохранительной деятельности, могли дать в распоряжение террористам информацию, которая помогла бы им в их подрывной деятельности, так как они представляют из себя не просто «преступников», a «противников»[53,p.518-520]. В тоже самое время, это очевидно, что Аль-Каида не может быть Высокой Договаривающейся Стороной в отношении Конвенций[13,p.714]. Но для того, что бы поддержать теорию «войны», была предложена такая конструкция, что Аль-Каида может являться «державой» (в английском языке используется слово «Power», которое более широкое по смыслу и, в принципе, может означат любого могущественного субъекта) в смысле статьи 2 части 3 Конвенций[17,p.528][21,para.11]. Из контекста указной части понятно, что скорее всего слово «держава» является синонимом стороны в данной Конвенции, однако, необходимо также разобрать варианты на наиболее важных с точки зрения международного права языках английском и французском. Национально освободительные движения хотели в свое время стать сторонами в Конвенции, но не смогли ввиду отсутствия государственности, то же произошло и с правительствами в изгнании[18,p.185].
Так, если мы посмотрим на английский текст четвертой Конвенции, то мы увидим, что термин «power», употребляется в статье 4, где обращается к гражданам, в статье 9, где так же обращается к гражданам, в статье 11, где упоминается территория, , 23, где упоминается предоставление безопасного прохода, так же как и в статьях 36 и 39.Так, если мы посмотрим французский текст, то мы увидим, что термин «рuissance» используется во всех случаях, что и английский «power», кроме статьи 4, где он заменен на «l'Etat», что явно говорит нам, что «роwer» и «puissance» являются синонимами «State» и «Etat» соответственно. Эта точка зрения так же подтверждается Travaux Preparatorie, где упоминаются «Powers», которые не могут быть сторонами Конвенции, так «non-contracting States» и «l'Etat non contractant»[68,p.24-25].

Таким образом, нормы международного гуманитарного права, регулирующие международный вооруженный конфликт, не могут применяться к конфликту между государством и негосударственным актором[29,p.529][63,p.326][50,p.202] [71,p.57][95,p.931].

Однако, международный вооруженный конфликт все еще возможен, если действия негосударственного актора могут быть атрибутированы государству[96,p.151].

Так Rowe утверждает, что после атаки 11 сентября, начался вооруженный конфликт, сторонами которого были США и Афганистан[73,p.312].

Сложно не согласиться, что конфликт между Коалиций и Афганистаном был международным вооруженным конфликтом, который длился с 7 октября 2001 года, т.е. с момента начала интервенции[4,p.65][96,p.157][62,p.44]. Однако, начался ли он с момента атаки 11 сентября? Если вооруженная атака, пересекающая количественную и качественную границу для начала военного конфликта, совершенная негосударственным актором, может быть атрибутирована государству, то возникает вооруженный конфликт между государством жертвой и государством «террористом»[17,p.919] [70,p.45][73,p.312][75,p.314-417]. При этом, для начала конфликта, государстве жертве даже не нужно предпринимать ответные меры против «террористов», международный военные конфликт стартует с момента самой атаки[41,para.84][44,para.75-76] [40,para.66]. Таким образом, вопрос о том, приведет ли атака негосударственного актора к международному вооруженному конфликту, целиком и полностью зависит от вопроса государственной ответственности[93,p.270]. 


\section{Атрибуция действия негосударственных акторов государству}

Есть точка зрения, что конфликт между США и Аль-Каидой может быть квалифицирован как конфликт между США и Афганистаном, где Аль-Каида выступает в качестве части вооруженных сил стороны, а именно как ополчение или добровольческие отряды в смысле статьи 4(a) (2) Конвенции III[4,p.66].В тоже самое время, необходимо отметить, что сам по себе факт, что они сражаются на одной стороне (против США) не достаточен для того, что бы выполнить требование принадлежности[4,p.66]. Более того, это еще более менее вероятно, что Аль-Каида смогла бы выполнить иные требования, которые выдвигаются к таким формированиям, а именно: а) имеют во главе лицо, ответственное за своих подчиненных, б) имеют определенный и явственно видимый издали отличительный знак, в) открыто носят оружие, г) соблюдают в своих действиях законы и обычаи войны. Но самое главное, статья 4 посвящена вопросу о статусе военнопленного, т.е. она относится к лицам, воюющим на стороне регулярных вооруженных сил в уже идущем международном вооруженном конфликте. Т.е. это подразумевает, что такие формирования сами по себе не могут стать причиной начала международного вооруженного конфликта, так как тест на начало военного конфликта изложен в статье 2 Конвенций и лишь после того, как он будет выполнен, можно говорить о статусе вооруженных сил в конфликте[61,p.466].

Однако, государства хоть и ответственны за действии своих органов, но в то же самое время е могут нести ответственность за действия частных лиц или их групп, которые просто организуются на его территории[35,p.18]. Но в тоже самое время, при определенных обстоятельствах, действия таких лиц могут быть атрибутированны государству, если они будут признаны его de facto органами.

Так в Nicaragua[36,p.140-150] Международный суд рассматривал вопрос исключительно об ответственности государства. Так Суд решил, что действия должностных лиц государства однозначно атрибутируются государству, т.е. полет военных летчиков на территорией Никарагуа, вызвал ответственность США[36,p.52-53]. Вовторых, на основании теста «эффективного контроля» Суд признал, что действия, совершенные неизвестными, которые фигурировали в отчетах ЦРУ как Unilaterally controlled Latino Assets, должны быть атрибутированны США. Так данные лица выполняли задачи по минированию трубопроводов, портов и атак на нефтедобывающие сооружения[36,p.45].Так UCLA финансировались правительством США, в их тренировке участвовали агенты ЦРУ, более того, все их действия совершались под их надзором[36,p.48]. Более того, часть актов была атрибутированна США, так как их агенты участвовали в планировании и непосредственном исполнении таких операций вместе c UCLA[36,p.62-65].

Касаемо Контрас, которые вели военные действия против Никарагуа с территории Гондураса и Коста-Рики, суд принял несколько иное решение. Так он признал зависимость Контрас от правительства США, в части финансирования и снабжения, т.е. США осуществляли на Контрас определенную степень контроля. Но она оказалась недостаточной, что бы произвести атрибуцию их действий США[36,p.65].

Правило «эффективного контроля» так же закреплено в Проекте статей о государственной ответственности [7,p.41]. Такой же принцип был использован Международным трибуналом по бывшей Югославии в деле Tadic[43,para.584-588], однако, позже оно было пересмотрено в пользу критерия общего контроля[43,para.32-34][93,p.276], который был высказан в особом мнении при вынесении первого решения судьей McDugal.

B Tadic ICTY суд рассматривал вопрос о том, был ли конфликт на территории бывшей Югославии международным или он носил немеждународный характер. Т.к. от этого зависело, сможет ли трибунал рассматривать вопрос о грубых нарушениях Женевских Конвенций[43,para.79-80]. Так для решения указанного вопроса, Суду предлагалось определить, действовали ли боснийские сербы от лица иного государства, а именно Федеративной республики Югославии. Следственная палата в своем решении пришла к выводу, что боснийские сербы не находились под эффективным контролем Югославии после того, как Югославия официально вывела свои войска с территории Боснии и Герцеговины. Т.е. конфликт должен был быть рассмотрен как имеющий не международный характер и жертвы Тадича могли воспользоваться лишь низким уровнем защиты, который предоставляла статья 3 Конвенций[43,para.607-608].

Но, Апелляционная палата пришла к другому решению, она обратилась к выводам Ираноамериканского трибунала, Европейского суда по правам человека и судебной практики национальных судов[41,para.124-130] и пришла к выводу, 
что международное право для разных ситуаций предлагает разные тесты. Так согласно выводам Суда, разный уровень контроля необходим для установления ответственности за действия вооруженных сил и индивидов[41,para.137]. Так в первую очередь ICTY признал правоту теста Nicaragua в отношении UCLA:

«когда необходим ответ на вопрос, является ли индивид или группа, которая не организована по военному приниипу де-факто государственным органом при выполнении конкретного действия, необходимо выяснить, были ли конкретные инструкции, относящиеся к совершению этого деяния выданы этим государством для индивида или группы; альтернативно, должно быть установлено, было ли противоправное деяние публично подтверждены или одобрены постфактум государством»[41,para.137].

Таким образом ICTY соглашается с тем, что атрибуция действий таких индивидов или групп индивидов должна происходить по правилам Nicaragua[36,para.86] или Tehran hostages [37,para.73-74]. В тоже самое время Апелляционная палата выработала иной подход для «вооруженных сил или вооруженных формирований». Так здесь Суд отверг критерии «эффективного контроля» и применил разработанный им критерий «общего контроля»:

«Однако, контроль со стороны государства над подчиненными ему вооруженными силами или вооруженными формированиями или военизированных формирований может быть общего характера (и должен включать больше, чем просто предоставление финансовой помощи или военного оборудования или обучения)...играет важную роль в организации, координации или планировании военных действий военной группы...»[41,para.137].

Конечно задачи Суда в делах Nicaragua и Tadic были различны. Так Международному суду необходимо было решить вопрос о том. Является ли государство ответственным за действия негосударственных акторов. В тоже самое время, ICTY не поднимал вопрос о государственной ответственности, а рассматривал вопрос о том, влияет ли общее вовлечение государства в конфликт на его квалификацию в качестве участника международного военного конфликта. Что дает некоторый повод для дискуссии о соотношений этих двух решений[15,p.249], вплоть до их противоречивости[100,c.84]. Так Meron утверждает, что Международный суд решал лишь вопрос о государственной ответственности и странно было бы применять указный тест к вопросу о вовлечении государства в международный конфликт. Так как применение теста Nicaragua в деле Tadic привело бы к его искусственному характеру и внутренней противоречивости[55,p.237].

Однако, в тоже самое время были высказаны мнения, что тесты в Nicaragua и Tadic разные и призваны решать разные задачи, так если Международный суд решает более специфическую задачу, то ICTY более общую, таким образом, конфликт между указанными двумя решениями не более чем выдуман[93,para.279]. Международный суд обратился к этому вопросу в Genocide case:

«логика не требует что бы идентичные тесты были использованы для решения разных вопросов: степень и характер участия государства в вооруженном конфликте на территории другого государства, которое требуется для конфликта, который можно охарактеризовать как международный, может очень хорошо и без логического несоответствия, отличаться от степени и характера участия в процессе возникновения ответственности этого государства за конкретного деяния, совершенные в ходе конфликта»[34,para.405].

Таким образом, Суд не только отличил дело Tadic от вопроса об ответственности государства, но и более того, признал что тест «общего контроля» может быть применен для определенных вопросов:

«Таким образом, тест «общего контроля» может быть применен для определения является ли вооруженный конфликт международным или носит немеждународный характер, который был единственным вопросом, разрешаемым Апелляционной палатой в дано деле. И в данном деле он может быть применим и удобен»[34,para.404].

Таким образом, мы можем заключить, что общий контроль над милитаризованными формированиями является достаточным для того, что бы установить вовлеченность государства в международный вооруженный конфликт. Т.е. он может быть распространен не только на ситуации, когда уже идущий вооруженный конфликт немеждународного характера меняет свою квалификацию, но и когда сам конфликт был начал действиями негосударственного актора.

Так в деле Tadic, как мы уже описали выше, Суд пришел к выводу, что конфликт может быть квалифицирован как международный, если негосударственный актор совершает деяния на территории государства, если последнее не выполняет 
свои обязательства должной осмотрительности. В данном случае, это дело, когда государство в последствии признало такое действие или оправдало его[37,para.73-74][42,para.137]. Для того, что бы избежать такой атрибуции, государство должно принять все необходимые меры для предотвращения или пресечения такого деяния. Спектр данных мер может зависеть от состоятельности государства и его обеспеченности, однако оно не может оправдать полное отсутствие каких-либо мер[101,с.81].

В отношении «Войны с терроризмом»неисполнение обязанности по выдаче определенного лица, которое было запрошено США от Афганистана могло служить причиной ответственности государства Афганистан за действия части лиц, которые действовали с его территории[73,p.308][19,p.920]. В тоже самое время, это вопрос о государственной ответственности, даже если Афганистан не выполнил законные требования США и не выдал им запрашиваемых лиц, это влечет лишь ответственность Афганистана[37,para.67], но не говорит о начале международного вооруженного конфликта самого по себе, хотя, есть и точка зрения, которая связывает ответственность с началом конфликта[9,p.578-582]. Так Суд четко отграничивает первую и вторую часть решения, а именно Иран был признан ответственным за оккупацию зданий посольства не самим фактом неисполнения своих обязательств должной осмотрительности, но в результате последующего одобрения произошедших событий[37,para.74].

Таким образом, сама по себе «война с терроризмом»не может быть признана международным вооруженным конфликтом сама по себе, хоть и конфликт между США и Афганистаном несомненно является таковым[62,p.45][22,p.347]. В тоже самое время, международный вооруженный конфликт не может существовать между государством с одной стороны и негосударственным актором с другой. Т.е. в тех случая когда «война с терроризмом» является международным вооруженным конфликтом, на самом деле это лишь конфликт между государством жертвой и государством поддерживающим терроризм, а не третья форма конфликта[48,p.234].

Таким образом, мы можем прийти к выводу, что «война с терроризмом» не является международным вооруженным конфликтом сама по себе, хотя отдельные военные операции в ее рамках могут быть квалифицированны таким образом.

\section{Война с терроризмом как вооруженный конфликт немеждународного характера}

Некоторые авторы считают, что «война с терроризмом» образует вооруженный конфликт немеждународного характера[47,p.182] [77,p.196-197]. Или, в некоторых случаях, считают, что правовой режим конфликта немеждународного характера наиболее удобен для таких вопросов[64,p.1632-1634]. Так, считается, что хотя нельзя с гарантией сказать, что международное гуманитарное право должно применяться при реализации государством своего право на самооборону против негосударственного актора, но международное гуманитарное право должно применяться, так как оно предоставляет удобный правовой режим и признано большинством стран[30,p.53-54].

Опять же, один из аспектов восприятия ситуации как вооруженного конфликта - уровень насилия.

В случае с немеждународными вооруженными конфликтами главное отделить вооружены конфликт от просто неподчинения органам власти и правопорядка, бунтов, гражданских неповиновений, т.е. те ситуации, с которыми государство в состоянии справиться, не привлекая вооруженные силы или военные методы воздействия. Это выражается также в критерии «длительного вооруженного насилия», который был сформулирован ICTY[43, para.70][45, para.184 , а затем подтверждается как ICTR [39, para.619] и в Международном уголовном суде (статья 8(2) (f) Статута). Однако, необходимо отметить, что данный критерий не закреплен в Конвенциях и Протоколах, а следовательно не может являться обязательным элементом[38,p.6]. В связи с чем, нам кажется убедительным мнение Межамериканской комиссии, которая постановила, что даже отдельные акты насилия могут требовать применения норм международного гуманитарного права, так как уровень насилия, милитаризованность участников могут этого требовать[33,para.155].

Статья 3 и Дополнительный протокол II были разработаны с целью регулирования гражданской войны и других ситуаций немеждународного насилия переступающие границу вооруженного конфликта. Ясно, что они в основном относятся к внутренним конфликтам, происходящих в пределах территориальных границ государства. Применимость Дополнительного протокола II даже четко ограничивается немеждународным вооруженным конфликтом, происходящим на террито- 
рии какого-либо государства между своими вооруженными силами и негосударственными акторами. Другими словами, Дополнительный протокол II не применяется, когда правительственные вооруженные силы противостоят негосударственным акторам исключительно за пределами их собственной территории или когда в вооруженном конфликте не участвуют правительственные силы. Это означает, что в отличие от статьи 3[76,para.4453], не все случаи немеждународного вооруженного конфликта охвачены Дополнительным протоколом II.

Статья 3 более свободно говорит о «вооруженном конфликте, не носящего международного характера и возникающего на территории одной из Высоких Договаривающихся Сторон». Она не требует, чтобы вооруженные силы государства участвовали в конфликте, ни того, что любая из сторон в конфликте была политически связана с этим государством, на территории которого противостояние происходит. Хотя статья 3 в первую очередь была адресована, для решения внутренних и колониальных проблем, ничего в подготовительных документах к этому положению не означает, что его формулировка была выбрана таким образом, чтобы исключить немеждународные вооруженные конфликты с участием на территории более чем одного государства, так, несмотря на то, что изначально существовала более широкая формулировка, которая предусматривала свое действие на территории одной или нескольких договаривающихся сторон[20,p.121], но в тоже самое время, она включала в себя положения о полном применении Конвенций в некоторых ситуациях, в связи и с чем, после изменения формулировки, делегатом, участвовавшим в разработке было подтверждено, что единственной целью переформулирования статьи была необходимость избежать предоставления статуса комбатанта неправительственной стороне[20,p.336][20,p.337] [20,p.333]. Таким образом, формулировка статьи 3 , говорит нам лишь о том, что немеждународный вооруженный конфликт должен происходить на территории одного или нескольких государств, которые являются сторонами Конвенции.

Этот порог, скорее всего, был достигнут 11 сентября, а также в ходе продолжающихся военных действий между правительством Афганистана и коалицией в Афганистане и остальными негосударственными акторами, будь то талибы или Аль-Каида[62,p.48]. Но уже это утверждение скорее всего показывает, не общий ответ по отношению к «войны с терроризмом»в целом, а индивидуальную оценку конкретного конфликта, который может являться ее частью. Следовательно, возможны отдельные сценарии, которые могли бы подтверждать вывод, что части «войны с терроризмом» являются вооруженным конфликтом немеждународного характера.

Во-первых, государство может приютить террористическую организацию, не поддерживая ее, но и не предпринимая никаких действий, чтобы предотвратить деятельность организации по причинам, не зависящим от государства. Таким образом, иностранное государство может вмешаться и принять меры в отношении организации - то есть в поддержку правительства, которое выступает против этих повстанцев. Такая ситуация была расценена как не международный вооруженный конфликт, а скорее вооруженный конфликт немеждународного характера[48,p.235].

Во-вторых, государство может столкнуться с одним или даже серией террористических актов на своей территории. Ярким примером является кризис с заложниками 23 по 26 октября 2002 года в Москве. Но также террористические акты и их серии ИРА в Северной Ирландии в 1970-х и 1980х годов, ЭТА во Франции и Испании с 1970, и Красной Армии в Германии в 1970-х годах могут попасть в такую категорию. Эти примеры показывают примеры спорадического насилия, которые все таки не выходят за пределы необходимого уровня насилия, нужного для применения международного гуманитарного права[70,p.367-369]. Они, как правило, подавляются силами полиции или иными правоохранительным органами и государству нет необходимости прибегать к использованию вооруженных сил. Террористические группы, совершающие такие теракты, не организованны по военному, не имеют соответствующей иерархии и не способны вести более менее регулярные военные действия. Они не рассматриваются как воюющая сторона и они не владеют какой-либо частью территории государства.

Таким образом, их действия, как правило, не составляют вооруженного конфликта[70,p.370] и подпадают под внутреннюю юрисдикцию государства, с учетом норм в области прав человека.

В-третьих, эта оценка может, возможно, изменится, если такие действия, как захват заложников происходят в рамках более широких рамках насилия, которое составляет вооруженный конфликт немеждународного характера. Это можно проиллюстрировать ситуацией с кризисом с заложниками в Москве в 2002 году, который сам по себе 
не является немеждународным вооруженным конфликтом. Тем не менее, такая оценка может быть изменена, если данное действие рассматривается как часть общей политики чеченских сил. Если конфликт в Чечне составляет вооруженный конфликт немеждународного характера и кризис с заложниками в Москве связан с этим конфликтом, то он мог бы стать частью этого конфликта и следовательно, в его отношении действовали бы нормы международного гуманитарного права, регулирующего внутренние вооруженные конфликты. Что касается первого вопроса, Россия Федерация всегда утверждала, что это было лишь полицейской операцией, когда ее войска вошли в Чечню, чтобы вынудить чеченцев покинуть Дагестан[70,p.31]. Тем не менее, большинство авторов утверждают, что порог немеждународного вооруженного конфликта был преодолен[70,p.358][16,p.145][1,p.741-767]. Касаясь второго вопроса, связь может состоять из линии прямой иерархии между захватчиками заложников и правительством Чеченской Республики. Эта правда трудно доказуемо[70,p.40]. Но даже если такая фактическая связь и существовала, то все равно будет трудно юридически подвести кризис с заложниками в Москве в рамки текущего немеждународного вооруженного конфликта. Это не может рассматриваться как вооруженные репрессалии, с помощью которых чеченские силы решили бы принудить правительство к определенным действиям в рамках военного конфликта. Таким образом, он скорее соответствует определению «террористического акта», чем военных действий, и необходимо сделать вывод, что, таким образом, не может рассматриваться как часть немеждународного вооруженного конфликта[70,p.372]. Таким образом, можно сделать вывод, что действия, которые традиционно рассматривается как «террористические акты» не достигают уровня немеждународного вооруженного конфликта, скорее всего, даже если они совершаются в связи с таким конфликтом.

\section{Война с терроризмом как третья форма вооруженного конфликта \\ Доктрина Правительства Соединенных Штатов Америки}

Вскоре после террористических атак в НьюЙорке и Вашингтоне правительство США называют эти события «военными действиями» и утверждают, что участвуют в «войне с терроризмом»[27]. Квалификация этого предприятия как «войны» была впоследствии утверждена несколькими ветвями власти и объединены в Стратегии национальной безопасности[90,p.5]. Правительство США определило своего противника в этой войне примерно как «Аль-Каида и ее аффилированные лица», «все террористические группы глобального масштаба « или просто « терроризм » как таковой, и подчеркнули, что нет никакого различия между «террористами»и «теми, кто сознательно укрывает или предоставляет им помощь».

Эти широкие описания вряд ли соответствуют минимальным требованиям для «стороны конфликта». Как указывалось выше, вооруженный конфликт происходит между организованными вооруженными группами, которые должны быть четко определены на основании объективных критериев.

Говоря о применимом праве, Правительство США утверждало, что ввиду квалификации «войны с терроризмом»как вооруженного конфликта, она должна регулироваться нормами международного гуманитарного права[87,p.2] но, что он составляет ни международный, ни немеждународный вооруженный конфликт по смыслу Женевских конвенций 1949 года[88,p.39] и, кроме того, «какие-либо обычные нормы международного права, которые относятся к вооруженным конфликтам, не связываются Президента США или вооруженные силы[88,p.39].

Некоторые из наиболее убедительных правовых аргументов в пользу этой точки зрения могут быть найдены в меморандуме Управления юрисконсульта министерства юстиции США от 9 января 2002 года, что исключает квалификацию войны против Аль-Каиды в качестве международного вооруженного конфликта по смыслу статьи 2 ЖК со следующим аргументом: «Неправительственные организации не могут быть участниками какого-либо из международных соглашений здесь, регулирующих законы и обычаи войны... Общая статья 2...Ограничивается только случаями объявленной войны или вооруженного конфликта между двумя или более из Высоких Договаривающихся Сторон. Аль-Каида не является Высокой Договаривающейся Стороной. В результате, обращение американских военных с членами Аль-Каиды не регулируется Женевскими конвенциями..»[88,p.11]. Эта интерпретация, была подтверждена распоряжением, подписанным президентом США Бушем 7 февраля 2002 года: «Я принимаю правовое заключение Министерства юстиции и определяю, что ни одно из положений Женевских конвенции не распространяется на 
наш конфликт с Аль-Каидой в Афганистане или в другом месте во всем мире, потому что, среди прочих причин, Аль-Каида не является высокой Договаривающейся Стороной»[6].

Это утверждение верно только в той степени, в которой оно приходит к выводу, что АльКаида, как не государства актор, не может быть участником международного вооруженного конфликта[51,p.262].

Следовательно, остается определить может ли «война с терроризмом» выполнить минимальные пороговые требования к немеждународного вооруженного конфликта. В связи с этим, меморандум говорит: «Аль-Каида не подпадает под общую статью 3, потому что нынешний конфликт не регулируется Женевскими конвенциями...Это конфликт «международного характера», а не внутренний вооруженный конфликт между сторонами, борющимися за контроль над правительством или территорией»[88,p.12].

Указ президента от 7 февраля 2002 года гласит: «Я также принимаю правовое заключение Министерства юстиции, и определяю, что общая статья 3 Женевских Конвенций не применяться к Аль-Каиде или Талибану задержанных, потому что, среди прочих причин, соответствующие конфликты международного масштаба и общая статья 3 применяется только к «вооруженным конфликтам, не носящего международного характера»[6].

Меморандум основан на чрезвычайно узком понятии немеждународного вооруженного конфликта, аналогично статье 1 ДП II, по существу, ограничивая его вооруженной борьбой за государственную власть или территорию между правительством страны и организованной повстанческой группой на территории этого государства. Следовательно, все конфликты, не связанные с национальным правительством, такие как конфликт в Ливане с 1975 по 1976 и недавнего времени или определенные эпизоды конфликта в Сомали и т.д. будут исключены из сферы немеждународного вооруженного конфликта. Это вряд ли можно сказать, чтобы это отношение поддерживалось большинством авторов и государств, в том числе Соединенными Штатами[89] в отношении иных конфликтов.

Наконец, учитывая, что положения Женевских конвенций о международных и немеждународных вооруженных конфликтах достигли статуса обычного права, меморандум утверждает, что «любые обычные нормы международного права, которые относятся к вооруженным конфликтам, не связывают Президента или вооруженные силы США[88,p.39].

По сути дела меморандум создает разрыв между понятиями международного и немеждународного вооруженного конфликта, принятыми в международном праве и пытается заполнить образовавшийся промежуток, вводя третью концепцию, которая описывается как «международная конфликт, где одна из сторон не государство». Этот новый вид вооруженного конфликта, регулируется ни законом прав человека, ни гуманитарного права, применимые в международных вооруженных конфликтах, ни статьей ЗЖК, ни обычным международным правом, и в котором поведение вооруженных сил должно быть урегулировано по соображениям военной необходимости и национальной безопасности.

Эффектом такой парадигмы является не применение минимальных стандартов гуманитарной защиты, которые являются обычным международным правом.

Таким образом, позиция правительства США находит себя рядом с печально известной прусской доктриной Kriegsraison- другим примером мощного государства, отказывающегося признать обязательную силу международного ограничения на ее поведение в условиях вооруженного конфликта. В ответ на это следует напомнить, что никакая мыслимая причина или ситуация, даже «справедливая война»[26], не может позволить государству освободить себя от императивных норм международного права. А третья концепция вооруженного конфликта служит именно этой цели, и чувство безнаказанности, которое неизбежно идет с ним, может, серьезно поставить под угрозу прогресс, достигнутый МГП в течение последних 150 лет, и поэтому она должна быть безоговорочно отвергнута[54,p.265].

В связи с этим, конечно, обнадеживает тот факт, что 29 июня 2006 года, Верховный суд США постановил, что статья 3 ЖК применяется к тому, что называется «конфликт, не носящий международного характера» между США и АльКаидой[92,p.67]. Суд считает, что термин «конфликт не международного характера» в статье 3 ЖК имеет буквальный смысл, и используется в отличие от конфликта между нациями. Суд, таким образом, прямо отклонил как «ошибочное» рассуждение американского правительства о том, что конфликт с Аль-Каидой, будучи «международного масштаба», не квалифицируется как «конфликт немеждународного характера», а также признал 
статью 3 ЖК применимой[92,p.69]. И хотя по прежнему остается под вопросом то, насколько США будут исполнять решение Верховного суда, тот факт, что концепция третьего конфликта была отвергнута как «ошибочная» говорит о том, что она не сможет служить для оправдания нарушения норм МГП.

\section{Доктрина смешанного конфликта Kretzemer'a}

Еще одной теорией, пытающейся урегулировать отношения, возникающие в связи с применением летальной силы в «войне с терроризмом», является доктрина Kretzmer’a, которая утверждает, что конфликт между «транснациональной террористической группой» и государством должен рассматриваться как немеждународный вооруженный конфликт, хотя он и признает, что правила немеждународного вооруженного конфликта официально не применяются. Он утверждает, что конфликт с Аль-Каидой не «был поглощен конфликтом с Афганистаном». Таким образом, лица, которые совершили вооруженное нападение на Соединенные Штаты были не мирными жителями, принимающими непосредственное участие в военных действиях между двумя государствами.

По мнению Kretzmer, конфликт «конфликт имеет в себе как международные так и не международные аспекты»[50,p.196]. Таким образом, он считает, что ни чисто правоохранительный подход, ни модель вооруженного конфликта не могут обеспечить достаточную базу для борьбы с «транснациональным терроризмом». Так как конфликт выходит за границы государства и не всегда способен подпасть под статью 3 ЖК или ДП II. Поэтому он видит необходимость введения элементов модели правоохранительной деятельности, то есть стандартов в области прав человека, в его «смешанную модель»[50,p.203]. Схожую позицию занимал Верховный суд Израиля[46,p.375-408].

Основная проблема, которую Kretzmer видит в отношении конфликтов между транснациональными террористическими группами и государством, как немеждународного вооруженных конфликтов - практически ничем не ограниченная возможность государства использовать летальную силу против лица, вместо того, что бы задержать его и судить[50,p.202]. Чтобы ограничить эти полномочия, он имплементирует стандарты в области прав человека: «единственным приемлемым оправданием для ликвидации подозреваемых в терроризме является защита потенциальных жертв террористических актов»[50,p.202].

Используя эти стандарты в области прав человека для формирования своего немеждународного вооруженного конфликта, Kretzmer утверждает, что применение силы должно соответствовать принципу пропорциональности и необходимости.

В результате получается, что государство не может использовать летальную силу против человека, если это не является необходимым, т.е. если существует реальная возможность задержать его и судить. Кроме того, должны быть убедительные доказательства, что подозреваемый активно участвует в планировании или подготовке новых террористических атак, хотя Kretzmer поддерживает подход «последнего окна возможностей» [50,p.203], так же необходимо отметить, что Schmitt занимает схожую позицию[78,p.110]. Касаемо пропорциональности, Kretzmer использует три фактора: Во-первых, опасность для жизни возможных жертв при дальнейшей деятельности террориста. Во-вторых, вероятность, что опасность для человеческой жизни реализуется, если деятельность подозреваемого террориста не будет немедленно прекращена. И в-третьих, опасность того, что гражданские лица будут убиты или ранены в результате нападения на подозреваемого террориста, под презумпцией того, что подозреваемые в терроризме не должны быть лишены жизни, когда есть реальная опасность, что гражданские лица будут убиты или пострадают, т.е. косвенный ущерб не допустим[50,p.204].

Так как Kretzmer видит опасность в возможности слишком вольного толкования этих норм государством, он предлагает институциональный механизм для устранения этой опасности: по аналогии с обязанностью провести эффективное расследование из практики ЕСПЧ. Kretzmer считает, что государства обязаны осуществлять эффективное расследование для того, чтобы определить, соответствует использование летальной силы стандартам, показанным выше. В противном случае, ответственные лица должны подвергнутся юридической ответственности[50,p.204]. Аналогичный подход, до степени смешения, предлагает Guiora, который считает террористов как «незаконных комбатантов», которые могут быть убиты на «поле боя». С другой стороны, он также ограничивает целевые убийства теми случаями, когда «арест лица не является вариантом», а также исключает лица, чьи действия не представляют угрозу безопасности и жизни иных лиц[32,p.331]. 
Kretzmer основывает свой подход на предположении, что применение международного права прав человека к такого рода конфликтам затруднено, так как потенциальные цели находятся вне пределов юрисдикции государства, а договорные режимы защиты прав человека как правило ограничены территорией стран-участников[50,p.202]. Здесь Kretzmer, скорее всего, ссылается на узкий и устаревшей подход к экстерриториальной применимости договоров по правам человека. Но даже критика, что режим прав человека является менее подходящим в связи с тем, что лица, о которых идет речь, часто действуют из-за рубежа не может быть убедительной. Так в случае признания «войны с терроризмом» как вооруженного конфликта немеждународного характера любое лицо, может быть объектом применения летальной силы. Осознавая это, Kretzmer прибегает к режиму прав человека во втором этапе. Которые он применяет для смягчения последствий квалификации «войны с терроризмом»как вооруженного конфликта, т.е. по сути дела, де факто говорит о применении стандартов права прав человека. Это похвально, что Kretzmer хочет избежать «лицензии на убийство» для государства. Но способ, которым он достигает эту цель кажется весьма сомнительным. Если он убежден, что правила в области прав человека должны применяться, зачем использовать парадигму международного гуманитарного права и внедрять в нее стандарты в области прав человека таким образом, что бы получить новый подход.

Тем не менее, такой подход несет в себе высокий риск в нем - он основан на предположении, правовой режим, применимый к «войне с терроризмом» это режим вооруженного конфликта. И хотя Kretzmer готов принять некоторые ограничения этого режима, другие - как Jinks[47,p.196-197] требуют применения ее в полном варианте. С точки зрения Otto, эта модель может быть воспринята теми, кто желает расширения полномочие в борьбе с терроризмом, т.к. как только парадигма военного конфликта будет воспринята, о дополнительных ограничениях быстро забудут[61,p.484].

\section{Вывод}

Таким образом, мы можем заключить, что понятие «война с терроризмом» может быть уместна в политическом и журналистском контексте, но это не юридическая категория[54,p.262-269] [25,p.889][5,p.21][65,p.64-66]. Хотя, необходимо отметить, что такая точка зрения имеет существенно больше сторонников сейчас нежели до событий $9 \backslash 11[3, p .800-818]$.

«Война с терроризмом» сама по себе не вооруженный конфликт[12,p.45-46][22,p.350][56,p.296] [96,p.157], ни международный, ни немеждународный. Однако, необходимо отметить, что право вооруженных конфликтов применяется к значительной части «войны с терроризмом». Но самое главное, это показывает, что вопрос о применимости международного гуманитарного права решает в соответствии с традиционными критериями, заложенными в международном праве.

Поскольку «война с терроризмом» не существует как юридическое явление, а лишь как риторика, то по сути дела она объединяет под одним наименованием множество военные или полицейских операций, и в то время как часть из них удовлетворяют требованиям для начала вооруженного конфликта, другие нет[61,p.485].

Этот вывод разделяют многие авторы, но тем не менее некоторые из них высказываются в поддержку применения международного гуманитарного права в ходе «войны с терроризмом», - в то же время признавая, что это не вооруженный конфликт de lege lata, но de lege ferenda.

В то время как это широко признается, что «война с терроризмом» не может считаться вооруженным конфликтом по определению, некоторые до сих пор считают закон войны как надлежащей правовой режим[95,p.945].

Однако, несмотря на это, они не испытывают желания давать противной стороне привилегии комбатантов, предпочитая считать их так называемыми «незаконными комбатантами». В этой связи, Kretzmer повторяет, что правовая парадигма военного конфликта не может быть применена, если только одна сторона имеет комбатантов[50,p.194]. Это, возможно, касается сути проблемы. Один из аргументов часто используется, чтобы показать неадекватность норм международного гуманитарного права в связи с «террористическими организациями», таких как Аль-Каида касается взаимности. «Хотя государства будут обязаны соблюдать правила международного гуманитарного права, «террористические организации» так поступать не будут. Государства, таким образом, обеспечивают преимущества международного гуманитарного права «для тех, кто нарушает все догматы права вооруженных конфликтов»[17,p.529].

Интересно, что некоторые авторы исходя их этого приходят к выводу, что не международное 
гуманитарное право является неподходящим правовым режимом, а то что государство в свою очередь так же должно быть освобождено от его пут: «Конфликт между Аль-Каидой и США не является симметричным в том виде, как обычная война: США не могут рассчитывать на получение каких-либо преимуществ от Аль-Каиды применяя к Аль-Каиде нормы международного гуманитарного права, учитывая то, как боевики Аль-Каиды относятся к пленным»[69,p.433]. Однако необходимо отметить, что применение норм международного гуманитарного права не связанно с взаимностью. Более того, нарушение одной из сторон конфликта своих обязательств относительно военнопленных или защиты гражданских лиц или объектов не может служить оправданием для аналогичного нарушения в порядке репрессалий. То же самое справедливо и для проблем, возникающих в отношении принципа различия. Так как «террористы» часто не отличают себя от гражданского населения или скрываются в гражданских объектах, из-за чего вооруженные силы часто будут неспособны их атаковать ввиду определенных запретов. Это, однако, не приводит к выводу, что государства не должны быть связаны запретом на неизбирательные нападения. Скорее это приводит нас к мысли, что гуманитарное право не лучший режим для борьбы с терроризмом глобальном смысле.

Эти проблемы показывают, что право вооруженных конфликтов не подходит как правовой режим, который должен применяться к «войне с терроризмом» [95,p.949]. Ибо основанная цель международного гуманитарного права это защита гражданских лиц во время военных действий. Если же одной из сторон конфликта является лицо или группа лиц, которая открыто нарушает все принципы и законы международного права военных конфликтов и более того, данный конфликт не подпадает под формальные определения, то идея о том, что бы насильно загнать его в данную парадигму выглядит сомнительно[61,p.486][54,p.268]. Даже Voneky, которая, как правило считает законы и обычаи войны в качестве пригодных к борьбе с терроризмом, признает, что выгоды от применения указной парадигмы не так уж и много[948].
Во-первых, она утверждает, что право войны более подробно, чем другие стандарты, - однако, тут можно сомневаться в отношении права человека. Во-вторых, она утверждает, что международное гуманитарное право предусматривает защиту от военных преступлений. Последнее, правда, но этот аргумент не является решающим. Индивидуальная уголовная ответственность не зависит от существования ситуации вооруженного конфликта или «мира». Правда, развитие международных уголовных трибуналов шло в контексте развития международного уголовного преследования за преступления, совершенные в контексте вооруженного конфликта. Но, с другой стороны, международное гуманитарное право допускает многие типы поведения, которые были бы незаконными, если они совершены за пределами вооруженного конфликта. Примерами являются концепция косвенного ущерба или тот факт, что международное гуманитарное право не знает общее правило приоритета ареста над лишением жизни[61,p.486]. Таким образом, можно сомневаться, действительно ли МГП обеспечивает лучшую защиту потенциальных жертв.

Поэтому, даже если вопрос о применимости de lege lataостается в стороне, то это еще далеко не ясно, будет ли международное гуманитарное право лучшим правовым режимом для удовлетворения требований борьбы с террористическими угрозами. Кроме того, даже если поддержать мнение, что международное гуманитарное право подходит к «войне с терроризмом», то надо быть готовы применять его постоянно. Ведь после того, как правовой режим международного гуманитарного права применен, государство не может выбрать иной режим, если он вдруг показался ему более удобным в данном случае. Таким образом, мы вынуждены согласиться, с Otto[61,p.486] и Newton[57,p.79], что, несмотря на то, что право является динамичной категорией и должно приспосабливаться под вызовы современности, нет никаких оснований для того, что утверждать, что текущая ситуация, а именно «война с терроризмом» требуют изменений в нормы, регулирующие вооруженный конфликт.

\section{Библиография:}

1. Abresch W. A Human Rights Law of Internal Armed Conflict: The European Court of Human Rights in Chechnya // European Journal of International Law. 2005.vol.16, pp. 741-767.

2. Anderson K. Targeted Killing in US counter Terrorism Strategy in: Wittes D. (ed.) Legislating War on Terror: An Agenda for the Reform. Washington. 2009. P.358-359.

3. Ansah T. War: Rhetoric \& Norm Creation in Response to Terror// Virginia Journal of International Law. (2003). vol.43, pp. 800-818 
4. Arai-Takahashi Y. Disentangling Legal Quagmires: The Legal Characterization of the Armed Conflicts in Afganistan since 6/7 October 2001 and Question of Prisoner of War Status // Yearbook of International Humanitarian Law. 2002. P.66

5. Arnold R. Terrorism and IHL: Common Denominator? In Arnold R., Hildbrand P. (eds) International Humanitarian Law and the 21th Century Conflicts: Changes and Challenges.Lausanne. 2005. P.21;

6. Associated Press, Prisoner Abuse Bush Order, 22 June 2004, § 2( a).

7. Aust H. The Normative Environment for Peace-On the Contribution of the ILC's Articles on State Responsibility in: Nolte G. (ed.), Peace through International Law: The Role of the International Law Commission, Heidelberg. 2009, pp.41

8. Baxi U. The "War on Terror" and the "War of Terror": Nomadic Multitudes, Aggressive Incumbents, and the "New" International Law // Osgoode Hall Law. Jornal (2005). vol.43, pp. 8-10;

9. Beard J. Military Action Against Terrorist under International Law. American's New War on Terror: The Case of Self-Defense under International Law // Harvard Journal of Law \& Public Policy. 2002.vol.25, pp.578-582

10. Biggio F., Neutralising the Threat: Reconsidering Existing Doctrines in the Emerging War on Terrorism // Case West Reserve Journal of Internationa Law. 2002. vol.34. P.4;

11. Borch F. Comparing Perl-Harbor and 9/11: Intelligence Failure? American Unpreparedness? Military Responsibility? // Journal of Military History.2003.vol.67.P.856

12. Borelli S. Treatment of Terrorist Suspects Captured Abroad in the War on Terror // International Review of the Red Cross.2005. vol.857.P.45-46;

13. Brooks R. War Everywhere: Rights, National Security Law, and the Law of Armed Conflicts in the Age of Terror // University Pennsylvania Law Review.2004.vol.153.P.714

14. Byers M., Nolte G. (eds.), United States Hegemony and the Foundations of International Law, Cambridge 2003; Frowein J. Der Terrorismus als Herausforderrung fur das Volkerrecht // Zeitschrift fur auslandishes offentliches Recht und Volkerrecht. 2002. P. 885-889;

15. Cassese A. International Law. Oxford. 2005. P. 249

16. Cherkasov A., Lokshina T. Chechnya: 10 Years of Armed Conflict. Helsenky Monitor. 2005. P.145;

17. Dalton J. What is War? Terrorism as War After 9/11 // Journal of International and Comparative Law.2006.vol.12.pp. 529

18. Detter I. The Laws of War. Cambridge. 2000. p.185

19. Dinstein Y. Comments on the Presentations by Nico Krisch and Carsten Stahn in: Walter C., Voneky S., Roben V., Schorkopf F. (eds.), Terrorism as a Challenge for National and International Law: Security versus Liberty?, Berlin 2004, pp 920

20. Diplomatic Conference 1949, Final Record, Vol.2-B, p.337;

21. European Commission for Democracy through Law, Opinion N.245/2003, para.11

22. Fizpatrick J. Jurisdiction of Military Commissions and the Ambiguous War on Terror // American Journal of International Law.2002.vol.96.P.350;

23. Fleischer A., White House press statement, 7 May 2003: Statement by the Press Secretary on the Geneva Convention

24. Franck T. Terrorism and the Right of Self-Defense // American Journal of Internationa Law.2001.vol.95. pp. 839-842;

25. Frowein J. Der Terrorismus als Herausforderrung fur das Volkerrecht // Zeitschrift fur auslandishes offentliches Recht und Volkerrecht. 2002. P.889;

26. George W. Bush, White House press conference, 11 October 2001.

27. George W. Bush, White House press statement: Statement by the President in Address to the Nation, 11 September 2001;

28. Goldman R. Certain Legal Questions and Issues Raised by the September 11 Aacks/Human Rights Brief. 2001. vol 9. pp.2-4

29. Greenwood C. War, Terrorism nad International Law // Current Legal Problems.2004.vol.56.P.529;

30. Gross E. The Struggle for Democracy Against Terrorism: Lessons from the United States, the United Kingdom, and Isarael. Charlottesvile. 2006. P.53-54

31. Gross, 15 Fla. J. Intl L. (2003), at 433-443.

32. Guiora A. Targetd Killing as Active Self-Defense // Case Western Reserve Journal of International Law.2004.vol.36.P.331

33. IACiHR, Abella (La Tablada) Case, para. 155

34. ICJ, Application of the Convention on the Prevention and Punishment of the Crime of Genocide, Bosnia and Herzegovina v. Serbia and Montenegro, Judgment of February 26, 2007, para. 404

35. ICJ, Corfu Channel, Merits, Judgment of April 9, 1949, I.C.J. Reports 1949, pp.18; Jennings R., Watts A. (eds.), Oppenheim’s International Law, Vol. I (Peace), 9 ‘ed., Harlow 1992, pp. 449-551

36. ICJ, Military and Paramilitary Activities in and against Nicaragua, Nicaragua v. United States of America, Judgment (Merits) of June 27, 1986, I.C.J. Reports 1986, pp. 14-150, at 50-51 (para. 86).

37. ICJ, United States Diplomatic and Consular Staff in Tehran, United States of America v. Iran, Merits, Judgment of May 24 , 1980, I.C.J. Reports 1980, pp. 35 (para. 74).

38. ICRC, Report Institute of International Humanitarian Law/ICRC-Roundtable. 2003. P.6

39. ICTR, Akayesu Case (Judgment of 2 September 1998), para.619

40. ICTY, Prosecutor v. Dario Kordic and Mario Cerkez, Case No. IT-95-14/2 ("Lasva Valley”), Judgment of February 26, 2001 , para. 66.

41. ICTY, Prosecutor v. Dusko Tadic, Case No. IT-94-1-A, Judgment (Merits Appeal) of July 15, 1999, reprinted in: 124 Intl L.R. (2003), pp. 118-119 (para. 137).

42. ICTY, Prosecutor v. Dusko Tadic, Case No. IT-94-1-A, Judgment of May 7, 1997, reprinted in: 112 Int'1 L.R. (1999), pp. 1-285, at $188-192$ (paras. 584-588).

43. ICTY, Prosecutor v. Dusko Tadic, Case No. IT-94-1-AR72, Decision on the Defence Motion for Interlocutory Appeal on jurisdiction of October 2, 1995, reprinted in: 105 Int'l L.R. (1997), pp. 419-648, at 495-497 (paras. 79-80).

44. ICTY, Prosecutor v. Tihomir Blaskic, Case No. IT-95-14-T, (“Lasva Valley”), Judgment of March 3, 2000, reprinted in: 122 Intl L.R. (2002), pp. 1-250, at 43 (paras. 75-76); 
45. ICTY, Tadic Case (Jurisdiction, 2 October 1995), para. 70; ICTY, Delalic Case (Judgment of 16 November 1998), para. 184

46. Israeli Supream Court. Public Committee against Torture in Israel, H.C.J. 5100/94, Judgment September 6, 1999. // Judgment of the Israel Supream Court: Fighting Terrorism within Law. Jerusalem. 2005. P.375-408

47. Jinks D. The Applicability of the Geneva Conventions to the "Global War on Terrorism // Virginia Journal of International Law. 2005. vol.46. pp.182;

48. Kooijmans P. Is there a Change in the his ad Bellum and if so, What Does it mean for the lus in Bello?', in: Lijnzaad L., von Sam-beck J., Tahzib-Lie B. (eds.), Making the Voice of Humanity Heard: Essays on Humanitarian Assistance and International Humanitarian Law in Honour of HRH Princess Margriet of the Netherlands, Leiden. 2004, pp. 235

49. Kotzur M. Krieg gegen den Terrorismus"-politische Rhetorik oder neue Konturen des "Kriegsbegriffes" im Volkerrecht? // 40 AVR (2002), pp. 454-479.

50. KretzimerD. Targeted Killing of Suspected Terrorist: Extrajudicial Execution or Legitimate Means of Defence? // European Journal of International Law.2005.vol.16.P.194

51. Lavoyer J-P. International Humanitarian Law and Terrorism in Lijnzaad L., von Sam-beck J., Tahzib-Lie B. (eds.), Making the Voice of Humanity Heard: Essays on Humanitarian Assistance and International Humanitarian Law in Honour of HRH Princess Margriet of the Netherlands, Leiden. 2004, pp. 262

52. Lietzau W. Combating Terrorism: The Consequences of Moving from Law Enforcement to War in Wippman D.; Evangelista M. (eds.), New Wars, New Laws? Applying the Laws of War in 21" Century Conflicts, Ardsley, N.Y. 2005, pp. 31-51, at 41-47;

53. McCarthy A. Terrorism on Trial: The Trials of al Qaeda // Case Western Reserve Journal of International Law.2004. vol.36.P.518-520

54. Melzer N. Targeted Killing in International law. Oxford. 2010. P.262-269;

55. Meron T. Classification of Armed Conflicts in Former Yugoslavia: Nicaragua Fallout // Amercan Journal of International Law.1998.vol.92.P.237

56. Neuman G. Humanitarian Law and Counterterrorst Force // European journal of International Law.2003.vol. 14.P.296;

57. Newton M. Unlawfull Belligerency After September 11: History Revisited and Law Revised in Wippman D., Evangelista M. New Wars, New Laws? Applying the Laws of War in 21th Century Conflicts.New York. 2005.P.79

58. OAS, Convocation of the Twenty-Fourth Meeting of Consultation of Ministers of Foreign Affairs to Serve as Organ of Consultation in Application of the Inter-American Treaty of Reciprocal Assistance, OEA/Ser G, CP/RES. 797 (1293/01), September 19, 2001;

59. OAS, Twenty-Fourth Meeting of Consultation of Ministers of Foreign Affairs, Resolution on Terrorist Threat to the Americas, OEA/Ser.F/I1.24, RC.24/RES.1 /01 (September 21, 2001).;

60. O'Connell M. The Legal Case Against the Global War on Terror // 36 Case W. Res. J. Intl L. (2004). vol.36, pp. 349-357, at 349;

61. Otto R. Targeted Killing and International Law.Springer.2010. P.486

62. Patel King F., Swaak-Goldman O. The Applicability of International Humanitarian Law to the "War against Terrorism" // Hague Yearbook of International Law. 2003. P.48

63. Paust J. War and Enemy Status after 9/11: Attacks on the Laws of War // Yale Journal of International Law. 2003. vol.28, P.326;

64. Peal R. Combatant Status Review Tribunals and the Uniqe Nature of the War on Terror // Vanderbilt Law Review.2005. vol.58.P.1632-1634

65. Pellet A. No, This is not War! // European Journal of International Law-Discussion Forum: The Attack on the World Trade Center: Legal Responses (October 3, 2001).

66. Pellet A., Tzankov V., Can a State Victim of a Terror Act have Recourse to Armed Force? // Humanitares VolkerrechtInformationsschriften. 2004, pp.71.

67. Pellet S., Pellet A. The Aftermath of September $11 / /$ Tilburg Foreign Law Review. 2002.vol.10.P.64-66

68. Pictet J. The Geneva Convention of 12 August 1949, Commentary, Fourth Geneva Convention.ICRC.1952. p. 24-25

69. Posner E. Terrorism and the Laws of War // Chicago Journal of International Law.2004.vol.5.P. 433

70. Quenivet N. The Moscow hostage crisis in the Light of the Armed Conflict in Chechnya // Yearbook of International Humanitarian Law.2001; Quenivet N. The Application of International Humanitarian Law to Situations of (counter)-Terrorist nature in Arnold R., Hildbrand P. (eds) International Humanitarian Law and the 21th Century Conflicts: Changes and Challenges.Lausanne.2005.

71. Rona G. Interesting Times for International Humanitarian Law: Challenges from the "War on Terror" // The Fletcher Forum of World Affairs. 2003. Vol.27:2.P.57;

72. Roth K. The Law of War in the War on Terror // Foreign Affairs.2004.vol.83.P.2;

73. Rowe P. Responses to Terror: The new "War" // Melbourne Journal of International Law.2002.vol.3.P.308;

74. Rowles P. Responses to Terrorism: Substantive and Procedural Constraints in International Law // 81 ASIL Proclamation.1987.vol.81, pp. 314.

75. Ruys T., Verhoeven S. Attacks by Private Actors and the Right of Self-Defence // Journal of Conflict and Security Law.2005. vol.10.P.314-417

76. Sandoz Y., Swinarski C., Zimmerman B. Commentary on the Additional Protocols of 8 June 1977 to the Geneva Conventions of 12 August 1949. Geneva. 1987. para.4453

77. Sassoli M. Unlawful combatants: the Law and Whether it nedd to be Revised // ASIL Proceeding.2003.vol.97, pp. 196-197.

78. Schmitt M. Counter-Terrorism and the Use of Force in International Law. Israeli Yearbook of Human Rights Law. 2002. P.110

79. Statman D. Targeted Killing // Theoretical inquiries in Law.2004.vol.5.P.197

80. Stevenson R. President Make it Clear: Phrase is "War on Terror" // New York Times. 2005. August 4.

81. The North Atlantic Treaty Organization, Statement by the North Atlantic Council of September 12, 2001 (Invocation Article V-attacks on US), Press Release (2001) 124; 
82. Travalio G. Terrorism, International Law and the Use of Military Force // Wisconsin International Law Journal.2000. vol.18.P.160-161

83. U.S. District Court for the Eastern District of Virginia, Alexandria Division, United States v. Zacarias Moussaoui (Superseding Indictment, June 2002), para. 2.

84. U.S. National Commission on Terrorist Attacks on the United States, The 9/11 Commission Report, Final Report, 2005 , p. 59.

85. UN SC Res. 1368 (September 12, 2001), Threats to International Peace and Security caused by Terrorist Acts, U.N. Doc. S/ RES/1368 (2001);

86. UN SC Res. 1373 (September 28, 2001), Threats to International Peace and Security caused by Terrorist Acts, U.N. Doc. S/ RES/1373 (2000);

87. US Department of Defence, Fact Sheet: Guantanamo Detainees.p.2

88. US Department of Justice, Memorandum: Application of Treaties, p. 39

89. US Department of State, Human Rights Report 2001 (Uganda).

90. US Government, National Security Strategy, p.5

91. US President George W. Bush, Address Before a Joint Session of the Congress on the United States Response to the Terrorist Attack of September 11, September 20, 2001. Weekly Compilation of Presidental Documents. 2001. N.38. P.1348

92. US Supreme Court, Hamdan v. Rumsfeld et al., pp. 69

93. van den Hole L. Towards a Test of the International Character of an Armed Conflict: Nicaragua and Tadic // Syracuse Journal of International Law and Commerce. 2005. vol.32, pp. 276

94. Voneky S. Die Anwendbarkeit des humanitaren Volkerrechts auf terroristische Akre and ihre Bekampfung in Fleck D. (ed.), Rechtsfragen der Terrorismusbekampfung durch Streitkrafte, Baden-Baden .2004, pp. 157;

95. Voneky S. The Fight against Terrorism and the Rules of the Law of Warfare, in: Walter C., Voneky S., Roben V., Schorkopf F. (eds) Terrorism as a Challenge for Naional and International Law: Security versus Liberty.Berlin.2004. P.948

96. Walter C. Zwischen Selbstverteidigung and Volkerstrafrecht: Bausteine for ein internationales Recht der "praventiven Terrorismus-Bekampfung", in: Fleck D. (ed.), Rechtsfragen der Terrorismusbekampfung durch Streitkrafte, Baden-Baden 2004, pp. 26-27;

97. Watkin K. Controlling Use of Force: A Role of for Human Rights in Contemporary Armed Conflicts // American Journal of Internationa Law. 2004. vol.98. p.t 5.

98. Wedgwood R. Combatants or Criminals? How Washington Should Handle Terrorists: Fighting a War Under its Rules'// Foreign Affairs.2004.vol.83.P.126-129.

99. Батырь В.А. Международное гуманитарное право. М. 2011. С.58

100. Гнатовский Н.Н. Гуманитарное право в международных судебных учреждениях: опасна ли институциональная фрагментация? // Международное правосудие. 2012. №1 с.84

101. Саврыга К. Международно-правовая ответственность государства нанимателя за противоправные действия частных военных и охранных компаний // Московский журнал международного права.2013. №4. с.81

\section{References (transliterated):}

1. Abresch W. A Human Rights Law of Internal Armed Conflict: The European Court of Human Rights in Chechnya // European Journal of International Law. 2005.vol.16, pp. 741-767.

2. Anderson K. Targeted Killing in US counter Terrorism Strategy in: Wittes D. (ed.) Legislating War on Terror: An Agenda for the Reform.Washington. 2009. P.358-359.

3. Ansah T. War: Rhetoric \& Norm Creation in Response to Terror// Virginia Journal of International Law. (2003). vol.43, pp. 800-818

4. Arai-Takahashi Y. Disentangling Legal Quagmires: The Legal Characterization of the Armed Conflicts in Afganistan since 6/7 October 2001 and Question of Prisoner of War Status // Yearbook of International Humanitarian Law. 2002. P.66

5. Arnold R. Terrorism and IHL: Common Denominator? In Arnold R., Hildbrand P. (eds) International Humanitarian Law and the 21th Century Conflicts: Changes and Challenges.Lausanne. 2005. P.21;

6. Aust H. The Normative Environment for Peace-On the Contribution of the ILC's Articles on State Responsibility in: Nolte G. (ed.), Peace through International Law: The Role of the International Law Commission, Heidelberg. 2009, pp.41

7. Baxi U. The "War on Terror" and the "War of Terror": Nomadic Multitudes, Aggressive Incumbents, and the "New" International Law // Osgoode Hall Law . Jornal (2005). vol.43, pp. 8-10;

8. Beard J. Military Action Against Terrorist under International Law. American's New War on Terror: The Case of Self-Defense under International Law // Harvard Journal of Law \& Public Policy. 2002.vol.25, pp.578-582

9. Biggio F., Neutralising the Threat: Reconsidering Existing Doctrines in the Emerging War on Terrorism // Case West Reserve Journal of Internationa Law. 2002. vol.34. P.4;

10. Borch F. Comparing Perl-Harbor and 9/11: Intelligence Failure? American Unpreparedness? Military Responsibility? // Journal of Military History.2003.vol.67.P.856

11. Borelli S. Treatment of Terrorist Suspects Captured Abroad in the War on Terror // International Review of the Red Cross.2005. vol.857.P.45-46;

12. Brooks R. War Everywhere: Rights, National Security Law, and the Law of Armed Conflicts in the Age of Terror // University Pennsylvania Law Review.2004.vol.153.P.714 
13. Byers M., Nolte G. (eds.), United States Hegemony and the Foundations of International Law, Cambridge 2003; Frowein J. Der Terrorismus als Herausforderrung fur das Volkerrecht // Zeitschrift fur auslandishes offentliches Recht und Volkerrecht. 2002. P. 885-889;

14. Cassese A. International Law. Oxford. 2005. P. 249

15. Cherkasov A., Lokshina T. Chechnya: 10 Years of Armed Conflict. Helsenky Monitor. 2005. P.145;

16. Dalton J. What is War? Terrorism as War After 9/11 // Journal of International and Comparative Law.2006.vol.12.pp. 529

17. Detter I. The Laws of War. Cambridge. 2000. p.185

18. Dinstein Y. Comments on the Presentations by Nico Krisch and Carsten Stahn in: Walter C., Voneky Roben V., Schorkopf F. (eds.), Terrorism as a Challenge for National and International Law: Security versus Liberty?, Berlin 2004, pp 920

19. Fizpatrick J. Jurisdiction of Military Commissions and the Ambiguous War on Terror // American Journal of International Law.2002.vol.96.P.350;

20. Fleischer A., White House press statement, 7 May 2003: Statement by the Press Secretary on the Geneva Convention

21. Franck T. Terrorism and the Right of Self-Defense // American Journal of Internationa Law.2001.vol.95. pp. 839-842;

22. Frowein J. Der Terrorismus als Herausforderrung fur das Volkerrecht // Zeitschrift fur auslandishes offentliches Recht und Volkerrecht. 2002. P.889;

23. George W. Bush, White House press conference, 11 October 2001.

24. George W. Bush, White House press statement: Statement by the President in Address to the Nation, 11 September 2001;

25. Goldman R. Certain Legal Questions and Issues Raised by the September 11 Aacks/Human Rights Brief. 2001. vol 9. pp.2-4

26. Greenwood C. War, Terrorism nad International Law // Current Legal Problems. 2004. vol.56. P.529;

27. Gross E. The Struggle for Democracy Against Terrorism: Lessons from the United States, the United Kingdom, and Isarael. Charlottesvile. 2006. P.53-54

28. Gross, 15 Fla. J. Intl L. (2003), at 433-443.

29. Guiora A. Targetd Killing as Active Self-Defense // Case Western Reserve Journal of International Law.2004.vol.36.P.331

30. Jinks D. The Applicability of the Geneva Conventions to the "Global War on Terrorism // Virginia Journal of International Law.2005.vol.46. pp.182;

31. Kooijmans P. Is there a Change in the his ad Bellum and if so, What Does it mean for the lus in Bello?', in: Lijnzaad L., von Sam-beck J., Tahzib-Lie B. (eds.), Making the Voice of Humanity Heard: Essays on Humanitarian Assistance and International Humanitarian Law in Honour of HRH Princess Margriet of the Netherlands, Leiden. 2004, pp. 235

32. Kotzur M. Krieg gegen den Terrorismus"-politische Rhetorik oder neue Konturen des "Kriegsbegriffes" im Volkerrecht? // 40 AVR (2002), pp. 454-479.

33. KretzimerD. Targeted Killing of Suspected Terrorist: Extrajudicial Execution or Legitimate Means of Defence? // European Journal of International Law.2005.vol.16.P.194

34. Lavoyer J-P. International Humanitarian Law and Terrorism in Lijnzaad L., von Sam-beck J., Tahzib-Lie B. (eds.), Making the Voice of Humanity Heard: Essays on Humanitarian Assistance and International Humanitarian Law in Honour of HRH Princess Margriet of the Netherlands, Leiden. 2004, pp. 262

35. Lietzau W. Combating Terrorism: The Consequences of Moving from Law Enforcement to War in Wippman D.; Evangelista M. (eds.), New Wars, New Laws? Applying the Laws of War in 21" Century Conflicts, Ardsley, N.Y. 2005, pp. 31-51, at 41-47;

36. McCarthy A. Terrorism on Trial: The Trials of al Qaeda // Case Western Reserve Journal of International Law.2004. vol.36.P.518-520

37. Melzer N. Targeted Killing in International law. Oxford. 2010. P.262-269;

38. Meron T. Classification of Armed Conflicts in Former Yugoslavia: Nicaragua Fallout // Amercan Journal of International Law.1998.vol.92.P.237

39. Neuman G. Humanitarian Law and Counterterrorst Force // European journal of International Law.2003.vol. 14.P.296;

40. Newton M. Unlawfull Belligerency After September 11: History Revisited and Law Revised in Wippman D., Evangelista M. New Wars, New Laws? Applying the Laws of War in 21th Century Conflicts.New York. 2005.P.79

41. O'Connell M. The Legal Case Against the Global War on Terror // 36 Case W. Res. J. Intl L. (2004). vol. 36, pp. 349-357, at 349;

42. Otto R. Targeted Killing and International Law.Springer.2010. P.486

43. Patel King F., Swaak-Goldman O. The Applicability of International Humanitarian Law to the "War against Terrorism" // Hague Yearbook of International Law. 2003. P.48

44. Paust J. War and Enemy Status after 9/11: Attacks on the Laws of War // Yale Journal of International Law. 2003. vol.28, P.326;

45. Peal R. Combatant Status Review Tribunals and the Uniqe Nature of the War on Terror // Vanderbilt Law Review.2005. vol.58.P.1632-1634

46. Pellet A. No, This is not War! // European Journal of International Law-Discussion Forum: The Attack on the World Trade Center: Legal Responses (October 3, 2001).

47. Pellet A., Tzankov V., Can a State Victim of a Terror Act have Recourse to Armed Force? // Humanitares VolkerrechtInformationsschriften.2004, pp.71.

48. Pellet S., Pellet A. The Aftermath of September $11 / /$ Tilburg Foreign Law Review. 2002.vol.10.P.64-66

49. Pictet J. The Geneva Convention of 12 August 1949, Commentary, Fourth Geneva Convention.ICRC.1952. p. 24-25

50. Posner E. Terrorism and the Laws of War // Chicago Journal of International Law.2004.vol.5.P. 433

51. Quenivet N. The Moscow hostage crisis in the Light of the Armed Conflict in Chechnya // Yearbook of International Humanitarian Law.2001.; Quenivet N. The Application of International Humanitarian Law to Situations of (counter)-Terrorist nature in Arnold R., Hildbrand P. (eds) International Humanitarian Law and the 21th Century Conflicts: Changes and Challenges.Lausanne.2005. 
DOI: $10.7256 / 1811-9018.2016 .4 .15056$

При цитировании этой статьи сноска на dоі обязательна

Право и политика $4(196) \cdot 2016$

52. Rona G. Interesting Times for International Humanitarian Law: Challenges from the "War on Terror" // The Fletcher Forum of World Affairs. 2003. Vol.27: 2.P.57;

53. Roth K. The Law of War in the War on Terror // Foreign Affairs.2004.vol.83.P.2;

54. Rowe P. Responses to Terror: The new "War" // Melbourne Journal of International Law.2002.vol.3.P.308;

55. Rowles P. Responses to Terrorism: Substantive and Procedural Constraints in International Law // 81 ASIL Proclamation.1987. vol.81, pp. 314.

56. Ruys T., Verhoeven S. Attacks by Private Actors and the Right of Self-Defence // Journal of Conflict and Security Law.2005. vol.10.P.314-417

57. Sandoz Y., Swinarski C., Zimmerman B. Commentary on the Additional Protocols of 8 June 1977 to the Geneva Conventions of 12 August 1949. Geneva. 1987. para.4453

58. Sassoli M. Unlawful combatants: the Law and Whether it nedd to be Revised // ASIL Proceeding.2003.vol.97, pp. 196-197.

59. Schmitt M. Counter-Terrorism and the Use of Force in International Law. Israeli Yearbook of Human Rights Law. 2002. P.110

60. Statman D. Targeted Killing // Theoretical inquiries in Law.2004.vol.5.P.197

61. Stevenson R. President Make it Clear: Phrase is "War on Terror" // New York Times. 2005. August 4.

62. Travalio G. Terrorism, International Law and the Use of Military Force // Wisconsin International Law Journal.2000. vol.18.P.160-161

63. van den Hole L. Towards a Test of the International Character of an Armed Conflict: Nicaragua and Tadic // Syracuse Journal of International Law and Commerce . 2005. vol.32, pp. 276

64. Voneky S. Die Anwendbarkeit des humanitaren Volkerrechts auf terroristische Akre and ihre Bekampfung in Fleck D. (ed.), Rechtsfragen der Terrorismusbekampfung durch Streitkrafte, Baden-Baden .2004, pp. 157;

65. Voneky S. The Fight against Terrorism and the Rules of the Law of Warfare, in: Walter C., Voneky S., Roben V., Schorkopf F. (eds) Terrorism as a Challenge for Naional and International Law: Security versus Liberty. Berlin. 2004. P.948

66. Walter C. Zwischen Selbstverteidigung and Volkerstrafrecht: Bausteine for ein internationales Recht der "praventiven Terrorismus-Bekampfung", in: Fleck D. (ed.), Rechtsfragen der Terrorismusbekampfung durch Streitkrafte, Baden-Baden 2004, pp. 26-27;

67. Watkin K. Controlling Use of Force : A Role of for Human Rights in Contemporary Armed Conflicts // American Journal of Internationa Law.2004.vol.98 .p.t 5.

68. Wedgwood R. Combatants or Criminals? How Washington Should Handle Terrorists: Fighting a War Under its Rules'// Foreign Affairs.2004.vol.83.P.126-129.

69. Batyr' V.A. Mezhdunarodnoe gumanitarnoe pravo.M. 2011. S.58

70. Gnatovskii N.N. Gumanitarnoe pravo v mezhdunarodnykh sudebnykh uchrezhdeniyakh: opasna li institutsional'naya fragmentatsiya? // Mezhdunarodnoe pravosudie.2012.№1 s.84

71. Savryga K. Mezhdunaro-pravovayaotvetstvennost' gosudarstva nanimatelya za protivopravnye deistviya chastnykh voennykh iokhrannykh kompanii // Moskovskii zhurnal mezhdunarodnogo prava.2013. №4. s.81 